\title{
An analysis of customer's purchase intention towards the green products and its effect on manufacturing: A statistical approach
}

\author{
Pravin Kumar*, Manoj Kumar Singh** and Saurabh Agrawal*** \\ * Department of Mechanical Engineering, Delhi Technological University, Delhi, India \\ ** Department of Mechanical Engineering, Pusa Institute of Technology, Delhi, India \\ *** Delhi School of Management, Delhi Technological University, Delhi, India \\ *Corresponding Author : pravin@dce.ac.in
}

\begin{abstract}
The study is based on finding the impact of consumer behavior on green manufacturing. The opinion of the consumer has been taken regarding the production of auto components in Delhi NCR. Most of the consumers are not aware of detailed manufacturing processes of the auto componentswhich leads to difficulties in finding the impact of consumer behaviour on production of the products having no direct application. To know the opinion of the consumer, a questionnaire survey is used to observe the consumer awareness and its impact on production of green product. The PLS-PM (partial Least Square-Path Modeling) is used to formulate the structural equation modelling. It was found that the perceived quality and cost of the product influencing consumer behaviour and purchase intention towards green consumptions. Some more green initiatives, advertising and promotion, and social welfare also influence the consumer significantly towards the use of green products.
\end{abstract}

Keywords: Partial least square path modeling; Environmental sensitiveness; Eco-consciousness; Consumer behaviour; Purchase intention; Green product production.

\section{INTRODUCTION}

The idea of green manufacturing emerges around 1970, still, it is not popular especially in a developing country. However, increasing environmental concern forces practitioners as well as researchers to consider this issue as a priority. The various business activities such as sourcing, manufacturing, logistics, and marketing are also somehow connected with the major environmental problems (Ali et al., 2011). But because of different consumer responses to different sustainable green strategies (Borin et al., 2013) the business organizations are not able to accurately understand the consumer behaviour towards green products causing poor green product development strategies. Albeit, consumers' pressure on the protection of the environment compelled the business organization to think about alternatives of conventional products such as the introduction of green design, green manufacturing, green packaging, or supporting cause-related promotions. Nasrollahi et al. (2019) addressed the environmental issues in location and capacity optimization in Glycyrrhiza cultivation. Aleisa and Alshayji (2019) analysed the reclamation of reuse of wastewater in Kuwait. Haque et al. (2014) analysed the characteristics of aggregate recycled concretes in Kuwait. The worldwide unmanageable and anti-environmental consumption forced society also to change their consumption and purchase behaviour for improvement of environmental sustainability (Jaisawal and Kant, 2018). Consumer behaviours are generally linked with the consumption pattern, which should not damage the natural environment and cause pollution (do Paco et al. 2019). The environmental responsiveness of an organization motivates the employee, 
increases the market share and brand loyalty of customers, and helps to remain competitive in the market. However, Barbarossa \& Pastore (2015) found that environmentally friendly product consumption is a costly affair and it leads to the reduced profit margin of the organizations.

Consumer behaviour towards the utilization of green products is one of the important factors to affect the production of green products. A lot of work has been done in this field, but the depth study of the factors responsible for green consumerism, specifically from the perspective of developing countries is still not been covered much. Moreover, the present study strives to fill the research gap by operationalizing and validating the relationship between green production and consumer intentions in India. In this study, the PLS-PM (Partial Least Square Path Modelling) approach of Structural Equation Modeling (SEM) technique has been used to find out the role of consumer behaviour, perceived quality purchase intentions, and their factors in the green product productions in India. PLS-PM can be used where the data is small as normalization is not required in this process. Various researchers used this method. In this study, Smart PLS software version 3.0 has been used due to its accuracy for smaller data. The main purposes of the study are:

(a) To outline the factors having an impact on various constructs of green manufacturing.

(b) To establish the relationship between the different constructs and indicators.

(c) To find the effect of green manufacturing on society.

This study is comprised of five sections: section 1 introduces the study; section 2 contains literature review and hypothesis formulation; section 3 discusses the research methodology; section 4 discusses the results of the research, and section 5 concludes the study.

\section{LITERATURE REVIEW}

The negative consequences of fast population growth are the fast exploitation of natural resources. It is observed that the global population growth rate is $1.18 \%$ per year (UN 2015). The optimal utilization and conservation of natural resources are very important for the present generation to maintain the sustainable growth of society and the country. Due to some constraints such as higher cost, lack of technology for reprocessing the materials, lack of awareness of green products among the consumers, lack of resources, etc., the popularity of green products among the consumers is not up to the mark. Thus, to know the consumer behaviour and purchase intention towards the green product this study is conducted so that the production of the green products can be enhanced to a large extent.

The production rate/volume of any product is directly related to the consumption rate. After the review of the literature, a generic list of factors influencing consumer behaviour was developed. The list was discussed with industry experts and concerned academicians. Based on their suggestions and after some modifications, it emerges out that the purchase intentions (PI) and consumer behaviour (CB) are the most influencing factors of the production of green products (GP). The perceived quality (PQ) of the product also influences consumer behaviour, brand loyalty (BL), and purchase intentions of the consumers as well as green production. Accordingly, to verify the emerging thoughts hypotheses have been developed.

Because of communication advancement, social media, and increasing consumer awareness, there is a need to understand consumer behaviour towards green purchases (Groening et al., 2018). Consumer behaviour towards green products is an outcome of environmental consciousness, which is influencing by multiple factors. Environmentally conscious consumers involve in buying products that do not have any negative impact on nature. The environmentallyconscious consumer also known as a green consumer avoids products that are harmful to health. Consumer belief that the ingredients of the green product require special preservation and production methods and hence adds production cost. Bennett and Williams (2011) estimated that green products are 16 to $100 \%$ costlier than conventional products. Green consumerism catalyzes organizations to be more socially responsible. The consumer intention to buy green products depends upon the quality, reliability, performance of the products, and his income level to afford the products 
as well as his awareness regarding the product delivery ability to protect the environment, green initiatives taken and the corporate social responsibility of the firms. The general consumer is motivated with immediate benefit from the products, whereas the environmentally-conscious consumer observes the benefit for the society as a whole (Rejikumar, 2016). Based on the above review, the following hypotheses have been formulated:

\section{$H_{1}:$ Consumer behaviour has a positive effect on purchase intention. \\ $\mathrm{H}_{2}$ : Consumer behaviour has a positive effect on brand loyalty. \\ $H_{3}$ : Consumer behaviour has a positive effect on green production.}

Tsiotsou (2006) defined perceived quality as a customer's apprehension about a product's overall performance. Some researchers found a direct relationship between perceived quality and purchase intentions whereas others did not find any relation between them. Hseih \& Li (2008) stated that higher Brand Loyalty of customers leads to a higher market share and helps in demanding relatively higher prices compared to those of competitors. Besides, loyal customers raise positive word-of-mouth promotion, defy competitors' strategies, and generate higher corporate profits, which further promotes the green product. However, Dabija et al. (2018) felt that customer brand loyalty helps companies overcome competitors. Whereas Chen et al. (2018) stated that brand loyalty positively enhances environmental consumerism and helps to maintain the environmental sustainability. Moisescu(2018) implied that consumer re-purchase behaviour alone cannot define his loyalty.

Álvarez-García et al. (2019) observed that brand loyalty is directly related to the emotional attachments of the consumer with the brands. Loyalty is the tendency to purchase a product or service of the same brand. Goriparthi and Tallapally (2017) found that the consumer can protect the environment by using green products which can be recycled and reuse to reduce the environmental impact. Although, the consumers are aware of the sustainability issue and want to purchase green products then also the green products are having only 1-3\% of the market share. Chen and Chang (2013) felt that if a company launches the product by misleading the customers about green claims, the customer would not rely on the brand. Chen et al., (2015) observed that if consumers are purchasing a product the first time, then the perceived quality of the products helps in the buying decisions. Ariffin et al., (2016) define perceived quality as consumer's perception about the superiority of the products over the same products available in the market by other brands. Perceived quality can be measured by service satisfaction, reliability, financial performance, dependability, environmental excellence, and ease of use. Perceived quality of products helps in increasing the purchase intentions of the products. The perceived quality of the products also helps in building brand loyalty. On the other hand, when a consumer perceives good about the product quality, it will help in building brand loyalty, which in turn help in enhancing green consumerism also. Based on the above analysis, the following hypotheses have been formulated:

\section{H5: Perceived quality has a positive effect on consumer behaviour. \\ H6: Perceived quality has a positive effect on brand loyalty. \\ H7: Perceived quality has a positive effect on green production. \\ H8: Green production has a positive effect on brand loyalty.}

H4: Perceived quality has a positive effect on the purchase intention of green products.

A product develops its trust when it fulfils the consumer's expectations. Chen and Chang (2012) observed that consumers assess the product based on their experience to minimize the perceived risk. It becomes more difficult to buy a product when accurate information about that product or service is not available. If a seller acts dishonestly in the absence of accurate information, it develops distrust and ultimately affects the perceived value of the products. This distrust develops an unwillingness among consumers to buy the products (Gregg and Walczak, 2008). Since consumer judgment is often based on asymmetric information, the perceived value of products positively influences their purchase intentions. Based on the literature review and survey the following hypotheses have been formulated: 
H9: Purchase intention has a positive effect on brand loyalty.

H10: Purchase intention has a positive effect on green production.

\section{RESEARCH METHODOLOGY}

To address the issues of consumer behaviour towards green consumption in India, a questionnaire was framed with the help of industry experts and a literature review. To process the statistical analysis, the individual response was recorded on a 5-points Likert scale. The survey was conducted, however, the response in the survey was not very good as many respondents were not aware of green products, and few were very reluctant to spare time for the same. In the case of PLS-PM analysis generally, the 10 times rules have been followed (Thompson et al., 1995) according to which the minimum sample size should be 10 times larger number of formative indicators used to measure the single constructs. Total 350 questionnaires were distributed amongst different ages, incomes, qualifications, and professional groups using personal contact and e-mail, out of which 131 responses were received. Out of these 131 responses, 19 responses were either incomplete or not very useful for the analysis; therefore, only 112 useful responses were left for analysis. The overall response rate is $32 \%$, which is more than $20 \%$ response as recommended by Malhotra and Grover (1998).

Structural equation modelling: Structural Equation Modeling (SEM) is a second-generation multivariate data analysis technique employed to assess the factors in the analysis phase. The relationship has been measured and tested by PLS-PM (SEM) method. Partial least Square Path Modeling (PLS-PM) developed by Herman Wold in the early 1980s is a regression analysis technique used for analyzing associations between latent variables and the items. PLS-PM is a variance based on structural equation modelling, which is used for exploratory research. PM is the diagrammatic representation of the relationship of hypotheses with variables contained two elements namely: the structure model, also called the inner model shows the relationship between the constructs, and the measurement model also called the outer model describes the relationship between constructs and their indicators (Sanchez, 2013).

\section{RESULTS AND DISCUSSION}

Reflective measurement models and formative measurement model techniques are used in PLS-PM. The reflective measurement models can be evaluated by checking the following factors: internal consistency reliability, indicator reliability, convergent validity, and discriminant validity. Reliability of constructs shows the ability to measure the same phenomenon accurately, repeatedly. The indicator's reliability can be checked from its outer loading, and it should be more than 0.7. However, the indicator's loading between 0.4 to 0.7 can be deleted to improve the composite reliability and AVE (Parvadavardini et al., 2016). The internal consistency can be measured through composite reliability with the help of Cronbach's alpha, which asses the reliability based on the inter-correlation of the indicators.

The value of Cronbach's $\alpha$ should be 0.6 to 0.9 (Bagozzi and Yi, 1988). The value of $\alpha$ less than 0.6 shows a lack of internal consistency reliability. Accordingly, in our study, the indicators whose outer loading was less than 0.7 have been deleted to improve the overall reliability of the construct. Validity can be checked through convergent validity and discriminant validity. The convergent validity indicates the extent up to which the indicators positively correlate with alternative indicators of the same construct and can be established through Average Variance Extracted (AVE) whose value should be more than 0.5 (Bagozzi and Yi, 1988).

The construct should be unique and should not capture the phenomena represented by others. This can be established from Discriminant validity. The Discriminant validity can be checked through cross-loading methods, Heterotrait -Monotrait Ratio (HTMT), and Fornell and Larcker method. In a cross-loading method, the loading of the constructs is being checked, which should be higher than its cross-loadings. Fornell and Larcker (1981) suggested that the "square root" of the AVE of each latent variable should be greater than the correlations among the latent variables 
to test the discriminant validity. In a cross-loading, the value can be changed when some additional constructs are added to the model whereas the value of HTMT does not change. The value of HTMT should be less than 0.85 for favourable results.

In the case of formative measurement models, the construct convergent validity can be examined using reflective measures through its correlation with an alternative measure of the constructs. The correlation between the constructs should be equal to 0.7 or more. Collinearity is a phenomenon in which one predictor (indicator) can be predicted from the others with a considerable degree of accuracy. The indicator's collinearity can be checked through the variance inflation factor (VIF). VIF shows the degree to which the standard error has been increased due to collinearity. The value of VIF should be $<0.5$ but there is always the issue of collinearity when the VIF value is $3-5$. Ideally, the value of VIF should be $<3$. If the value of outer loading is $\geq 0.5$, the indicator should be retained otherwise the formative indicator should be removed from the models. In this study, both formative and reflective measurement models have been used. The PQ, CB, PI, BL have a formative loading whereas GP has reflective loadings. Table 1 shows the discriminant validity measurements using the Fornell-Larcker criterion for a reflective construct. To check the correlation of one measure with other measures of the same construct using different indicators, a convergent validity test has been used.

Table 1. Discriminant Validity using Fornell- Larcker Criterion

\begin{tabular}{|c|c|c|c|c|c|}
\hline Constructs & BL & CB & GP & PI & PQ \\
\hline BL & & & & & \\
\hline $\mathrm{CB}$ & 0.854 & & & & \\
\hline $\mathrm{GP}$ & 0.796 & 0.806 & 0.715 & & \\
\hline $\mathrm{PI}$ & 0.597 & 0.669 & 0.693 & & \\
\hline $\mathrm{PQ}$ & 0.847 & 0.867 & 0.810 & 0.677 & \\
\hline
\end{tabular}

In this research, the collinearity of the indicators through the formative indicator's VIF value has also been checked. From the results as mentioned in Table 2, it is observed that the maximum VIF value is 2.90 which is below the threshold value of 5and collinearity is not an issue for estimation of PLS-PM as it is much below the critical value. The relevance and significance of the formative indicators are checked by their outer weight. The outer weight is the result of multiple regression of construct as a dependent variable and indicator as to the independent variables (Hair et al., 2011). The outer weight shows the relative contribution to forming the construct. If indicators are not correlated to each other, the maximum possible outer weight becomes $1 / V_{n}$ where $n$ is the number of indicators. When outer loading is more than 0.50 , the indicator would generally be retained despite the non-significant outer weight. The significance of the outer weight is checked through the bootstrapping process. In this study, the outer weight/loading shown in Table 2 and the ' $p$ ' value and ' $t$ ' value shown in Table 3 shows that all the formative indicators are significant at the $5 \%$ level.

The structural model can be evaluated through the coefficient of determination $\left(R^{2}\right)$, effect size $\left(f^{2}\right)$, and the statistical significance of the structural path coefficients. $R^{2}$ measures the model's predictive accuracy. The value of $R^{2}$ equal to $0.75,0.5$, and 0.2 can be considered as substantial, moderate, and weak in marketing research (Hair et al., 2011). The $f^{2}$ effect size measures the impact of omitted constructs due to a change in the value of $R^{2}$. 
Table 2. Measurement of collinearity issue and the significance of formative indicators

\begin{tabular}{|c|c|c|c|c|c|}
\hline $\begin{array}{l}\text { S. } \\
\text { No. }\end{array}$ & $\begin{array}{l}\text { Formative } \\
\text { Constructs }\end{array}$ & Formative Indicators & $\begin{array}{l}\text { Outer weight/ } \\
\text { Outer Loadings }\end{array}$ & $\begin{array}{c}\text { Cronbach's } \\
\alpha\end{array}$ & VIF \\
\hline \multirow{4}{*}{1.} & \multirow{4}{*}{$\begin{array}{l}\text { Purchase } \\
\text { Intentions } \\
\text { (PI) }\end{array}$} & Need Fulfillment (PI-1) & $0.278 / 0.720$ & \multirow{4}{*}{0.695} & 1.546 \\
\hline & & Environmental Consciousness (PI-2) & $0.338 / 0.709$ & & 1.470 \\
\hline & & Personal Attention (PI-3) & $0.383 / 0.731$ & & 1.291 \\
\hline & & Post Sales-Service (PI-4) & $0.384 / 0.730$ & & 1.278 \\
\hline \multirow{5}{*}{2.} & \multirow{5}{*}{$\begin{array}{c}\text { Perceived } \\
\text { Quality (PQ) }\end{array}$} & Consumer Producer relationship (PQ-1) & $0.277 / 0.756$ & \multirow{5}{*}{0.845} & 2.775 \\
\hline & & Empathy (PQ-2) & $0.297 / 0.792$ & & 2.071 \\
\hline & & Responsiveness (PQ-3) & $0.209 / 0.806$ & & 2.164 \\
\hline & & Reliability (PQ-4) & $0.209 / 0.758$ & & 2.900 \\
\hline & & Assurance (PQ-5) & $0.278 / 0.819$ & & 2.300 \\
\hline \multirow{5}{*}{3.} & \multirow{5}{*}{$\begin{array}{l}\text { Consumer } \\
\text { Behaviour } \\
\text { (CB) }\end{array}$} & Product Cost (CB-1) & $0.302 / 0.750$ & \multirow{5}{*}{0.852} & 2.388 \\
\hline & & Green Initiatives (CB-2) & $0.515 / 0.770$ & & 1.243 \\
\hline & & (CSR)Social Welfare (CB-3) & $-0.0580 / 0.708$ & & 2.542 \\
\hline & & Product Quality (CB-4) & $0.365 / 0.780$ & & 1.803 \\
\hline & & Income Level (CB-5) & $0.176 / 0.762$ & & 2.705 \\
\hline \multirow{5}{*}{4.} & \multirow{5}{*}{$\begin{array}{c}\text { Brand } \\
\text { Loyalty (BL) }\end{array}$} & Organisational Commitment (BL-1) & $0.247 / 0.790$ & \multirow{5}{*}{0.833} & 2.070 \\
\hline & & Respect for Rule of Law (BL-2) & $0.199 / 0.758$ & & 2.079 \\
\hline & & Advertising \& Promotions (BL-3) & $0.425 / 0.718$ & & 1.199 \\
\hline & & Transparency in dealing (BL-4) & 0.1780 .789 & & 2.274 \\
\hline & & Expectations (BL-5) & 0.2820 .740 & & 1.701 \\
\hline \multirow{6}{*}{5.} & \multirow{6}{*}{$\begin{array}{l}\text { Green } \\
\text { Production } \\
\text { (GP) }\end{array}$} & Use of alternative materials/ Green Design (GP-1) & $0.213 / 0.703$ & \multirow{6}{*}{0.855} & 1.318 \\
\hline & & Green Packaging (GP-2) & $0.226 / 0.747$ & & 2.861 \\
\hline & & Energy Conservation (GP-3) & $0.213 / 0.703$ & & 1.598 \\
\hline & & Waste Management (GP-4) & $0.215 / 0.709$ & & 1.852 \\
\hline & & Improvement in Life Expectancy (GP-5) & $0.216 / 0.714$ & & 2.791 \\
\hline & & Production Cost (GP-6) & $0.216 / 0.712$ & & 2.886 \\
\hline
\end{tabular}


The $f^{2}$ value of $0.02,0.15$, and 0.35 ate represents small, medium, and large effects, respectively. The $f^{2}$ is not relevant in this study as no constructs have been omitted. Bootstrapping is used to find the significance of path coefficients. The critical ' $t$ ' value should be 1.65 (significance level 10\%), 1.96 (significance level 5\%), and 2.57 (significant level $1 \%$ ) for a two-tailed test, and ' $p$ ' value should be less than 0.10 (significant level 10\%), 0.05 (Significance level 5\%) and 0.01 (significant level 1\%). The $5 \%$ significance level has been taken in this study.

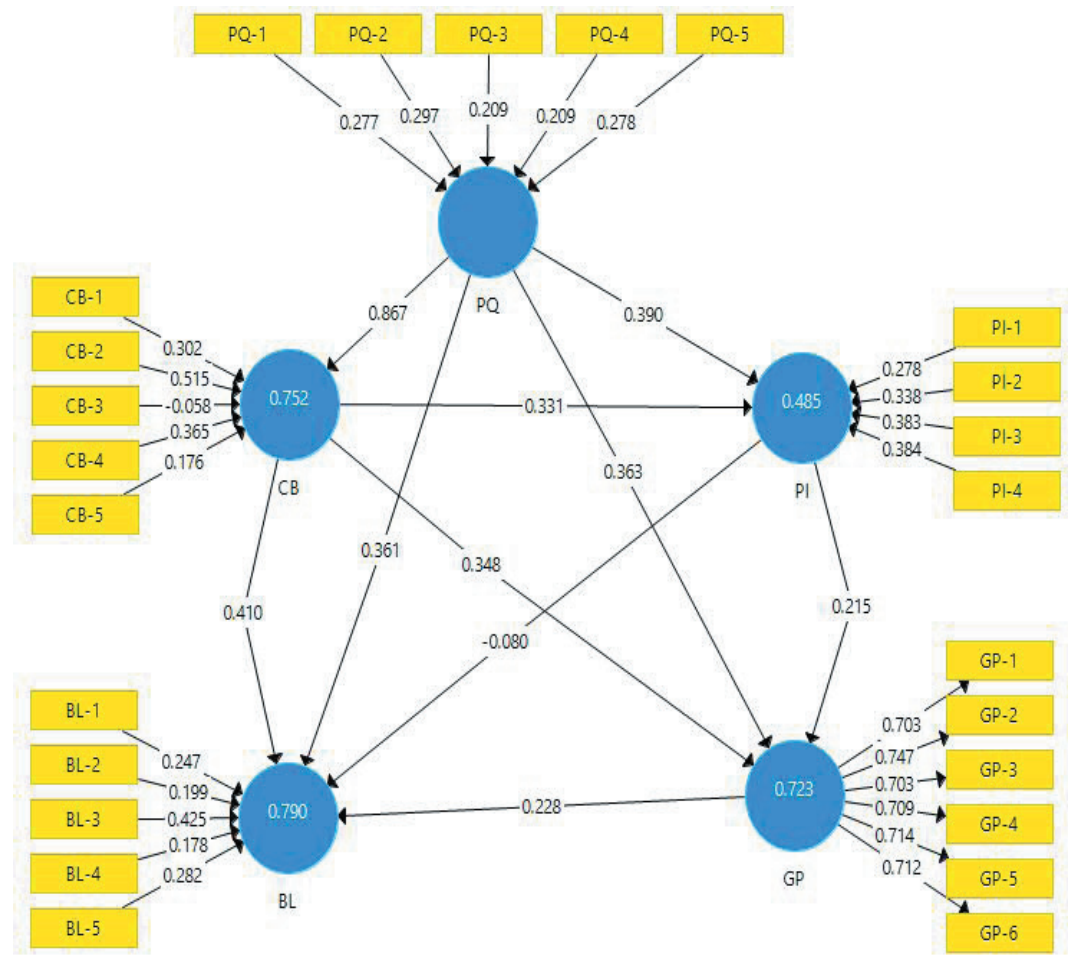

Figure 2. PLS-PM Model

The perceived quality of the product has a strong effect on changing consumer behaviour and purchase intentions as it explains $75.2 \%$ of the variance in consumer behaviour and $48.5 \%$ of the variance in purchase intentions of the consumer. The perceived quality of the product besides improving the consumer behaviour for purchase intentions of green products, also play an important role in improving the production of green products as they explain $72.3 \%$ of the variance in green production. The perceived quality of the products along with changing consumer behaviour and purchase intentions with green production also strongly helping in improving brand loyalty of the corporate as together they explain $79 \%$ variance in brand loyalty.

The path coefficients as shown in Table 3 also show that the perceived quality has the strongest effect on consumer behaviour (0.867) followed by Price intention (0.390), green production (0.363), and brand loyalty (0.361). The path coefficient also shows that brand loyalty is strongly improved by consumer behaviour ( 0.410$)$ rather than green production (0.228) whereas price intentions $(-0.08)$ has a negative impact on brand loyalty. Consumer behaviour has a moderate impact on green production $(0.348)$ and price intentions $(0.331)$ and the impact of price intentions on green production $(0.215)$ is moderate as shown in Figure 2 . The perceived quality of the product also has a very strong influence in improving price intentions of the consumer (hypothesis $\mathrm{H}_{4}$ ), improving consumer behaviour towards green consumptions $\left(\mathrm{H}_{5}\right)$, increasing brand loyalty (hypothesis $\mathrm{H}_{6}$ ), and finally raising green productions (hypothesis $\mathrm{H}_{7}$ ) and hence accepted these hypotheses. The goods purchase intentions of the consumer also help in improving the green production (hypothesis $\mathrm{H}_{10}$ ) and hence the hypothesis is accepted, but the role of green productions and price 
intentions in improving brand loyalty has not been proved, hence, the hypothesis $\mathrm{H}_{8}$ and $\mathrm{H}_{9}$ are rejected.

Table 3. Hypothesis Testing Results

\begin{tabular}{|c|c|c|c|c|c|}
\hline Hypothesis & Relationship & Path coefficient & t- statistics & p-values & Result \\
\hline $\mathrm{H}_{1}$ & $\mathrm{CB} \rightarrow \mathrm{PI}$ & 0.331 & 2.247 & 0.049 & Accepted \\
\hline $\mathrm{H}_{2}$ & $\mathrm{CB} \rightarrow \mathrm{BL}$ & 0.410 & 3.350 & 0.000 & Accepted \\
\hline $\mathrm{H}_{3}$ & $\mathrm{CB} \rightarrow \mathrm{GP}$ & 0.348 & 2.247 & 0.021 & Accepted \\
\hline $\mathrm{H}_{4}$ & $\mathrm{PQ} \rightarrow \mathrm{PI}$ & 0.390 & 2.614 & 0.011 & Accepted \\
\hline $\mathrm{H}_{5}$ & $\mathrm{PQ} \rightarrow \mathrm{CB}$ & 0.867 & 27.478 & 0.000 & Accepted \\
\hline $\mathrm{H}_{6}$ & $\mathrm{PQ} \rightarrow \mathrm{BL}$ & 0.361 & 2.840 & 0.004 & Accepted \\
\hline $\mathrm{H}_{7}$ & $\mathrm{PQ} \rightarrow \mathrm{GP}$ & 0.363 & 2.187 & 0.036 & Accepted \\
\hline $\mathrm{H}_{8}$ & $\mathrm{GP} \rightarrow \mathrm{BL}$ & 0.228 & 1.732 & 0.109 & Rejected \\
\hline $\mathrm{H}_{9}$ & $\mathrm{PI} \rightarrow \mathrm{BL}$ & -0.080 & 0.881 & 0.370 & Rejected \\
\hline $\mathrm{H}_{10}$ & $\mathrm{PI} \rightarrow \mathrm{GP}$ & 0.215 & 2.080 & 0.032 & Accepted \\
\hline
\end{tabular}

\section{CONCLUSION}

Consumer behaviour influences the production of most products. Although, the issue of green manufacturing is very old still the green production has not received the proper attention of the manufacturers. The main reason for the poor response of the consumers in the utilization of green products is the lack of popularization of green products. In this research, the authors have some important factors that need to be addressed to improve the consumption patterns of green products. It has been observed that environmental problems cannot be solved by only sustainable production strategies. It also requires a change in consumer behaviour and price strategy. The study has proved that the perceived quality of the products has the highest impact in changing consumer behaviour for green utilization. The consumer of developing countries is very much price sensitive and it is observed in the study that the price intentions of the consumer also have a great impact on green production. It has been observed that the need fulfilment and environmental consciousness of the consumer, personal attention given by the manufacturer, and post-sales service have a major role in improving the price intentions of the consumer. Whereas the product cost, green initiatives, and product quality have a great impact on changing consumer behaviour for green utilization. However, the consumerproducer relationship, empathy, responsiveness, reliability, and assurance are the main factors that help in improving the perceived quality of the product.

Limitations of the research: The number of observations was based on the responses of 112 respondents only. A survey based on a broad section of consumers may be required for more reliable results. 


\section{REFERENCES}

Aleisa, E. \& Alshayji, K. 2019. Analysis on Reclamation and Reuse of Wastewater in Kuwait. Journal of Engineering Research, 7(1):1-13.

Ali, A., Khan, A. A., Ahmed, I. \& Shahzad, W. 2011. Determinants of Pakistani consumers' green purchase behaviour: Some insights from a developing country. International Journal of Business and Social Science, 2(3): 217-226.

Álvarez-García, J., del Carmen Cortés-Domínguez, M., del Río, M. D. L. C. \& Simonetti, B. 2019. Influence of brand equity on the behavioural attitudes of customers: Spanish Tourist Paradores. Quality \& Quantity, 54 (5): 1401-1427.

Ariffin, S., Yusof, J. M., Putit, L. \& Shah, M. I. A. 2016. Factors influencing perceived quality and repurchase intention towards green products. Procedia Economics and Finance, 37(16): 391-396.

Bagozzi, R. P. \& Yi, Y. 1988. On the evaluation of structural equation models. Journal of the academy of marketing science, 16(1): 74-94.

Barbarossa, C. \& Pastore, A. 2015. Why environmentally conscious consumers do not purchase green products. Qualitative Market Research: An International Journal, 18(2):188-209.

Bennett, G. \& Williams, F. 2011. Mainstream Green: Moving sustainability from niche to normal. New York: Ogilvy \& Mather.

Borin, N., Lindsey - Mullikin, J. \& Krishnan, R. 2013. An analysis of consumer reactions to green strategies. Journal of Product \& Brand Management., 22(2): 118-128.

Chen, C. C., Chen, C. W. \& Tung, Y. C. 2018. Exploring the consumer behaviour of intention to purchase green products in belt and road countries: An empirical analysis. Sustainability, 10(3): 854.

Chen, Y. S., Lin, C. Y. \& Weng, C. S. 2015. The influence of environmental friendliness on green trust: The mediation effects of green satisfaction and green perceived quality. Sustainability, 7(8): 10135-10152.

Chen, Y.S. \& Chang, C.H. 2013, Towards green trust: the influences of green perceived quality, green perceived risk, and green satisfaction, Management Decision, 51(1): 63-82.

hen, Y.S. \& Chang, C.H. 2012. Enhance green purchase intentions: The roles of green perceived value, green perceived risk, and green trust. Management Decision, 50(3): 502-520.

Dabija, D. C., Bejan, B. M. \& Grant, D. B. 2018. The impact of consumer green behaviour on green loyalty among retail formats: A Romanian case study. Moravian geographical reports, 26(3): 173-185.

do Paco, A., Shiel, C. \& Alves, H. 2019. A new model for testing green consumer behaviour. Journal of cleaner production, 207: 998-1006.

Fornell, C. \& Larcker, D. F. 1981. Evaluating structural equation models with unobservable variables and measurement error. Journal of marketing research, 18(1): 39-50.

Goriparthi, R. K. \& Tallapally, M. 2017. Consumers' attitude in green purchasing. FIIB Business Review, 6(1): $34-44$.

Gregg, D. G. \& Walczak, S. 2008. Dressing your online auction business for success: An experiment comparing two eBay businesses. Mis Quarterly, 653-670, 32(3): 653-70.

Groening, C., Sarkis, J. \& Zhu, Q. 2018. Green marketing consumer-level theory review: A compendium of applied theories and further research directions. Journal of Cleaner Production, 172: 1848-1866. 
Hair, J. F.,Ringle, C. M. \& Sarstedt, M. 2011. PLS-SEM: Indeed a silver bullet. Journal of Marketing theory and Practice, 19(2): 139-152.

Haque, M. N., Al-Yaqout, A. F., Sreekala, V. \& El-Hawary, M. 2014. Characteristics of recycled aggregate concretes produced in Kuwait: a case study. Journal of Engineering Research, 4(2): 1-17.

Hsieh, A. T. \& Li, C. K. 2008. The moderating effect of brand image on public relations perception and customer loyalty. Marketing intelligence \& planning,26(1): 26-42.

Jaiswal, D. \& Kant, R. 2018. Green purchasing behaviour: A conceptual framework and empirical investigation of Indian consumers. Journal of Retailing and Consumer Services, 41: 60-69.

Malhotra, M. K. \& Grover, V. 1998. An assessment of survey research in POM: from constructs to theory. Journal of operations management, 16(4): 407-425.

Moisescu, O. I. 2018. From perceptual corporate sustainability to customer loyalty: A multi-sectorial investigation in a developing country. Economic research-Ekonomskaistraživanja, 31(1): 55-72.

Nasrollahi, M., Razmi, J. \& Ghodsi, R. 2019. A combined fuzzy PCA approach for location optimization and capacity planning in Glycyrrhizae green supply network design. Journal of Engineering Research, 7(4):261-275.

Parvadavardini, S.,Vivek, N. \& Devadasan, S. R. 2016. Impact of quality management practices on quality performance and financial performance: evidence from Indian manufacturing companies. Total Quality Management \& Business Excellence, 27(5-6): 507-530.

Rejikumar, G. 2016. Antecedents of green purchase behaviour: An examination of moderating role of green wash fear. Global Business Review, 17(2): 332-350.

Sanchez, G. 2013. PLS path modeling with R. Berkeley: Trowchez Editions, 383: 2013.

Thompson, R., Barclay, D. W. \& Higgins, C. A. 1995. The partial least squares approach to causal modeling: Personal computer adoption and use as an illustration. Technology studies: special issue on Research Methodology, 2(2): 284-324.

Tsiotsou, R. 2006. The role of perceived product quality and overall satisfaction on purchase intentions. International journal of consumer studies, 30(2): 207-217. 